\title{
CONSULTAS CIUDADANAS LOCALES: \\ ENTRE LA LEGITIMACIÓN GUBERNAMENTAL Y EL EMPODERAMIENTO CIUDADANO
}

\author{
Quím BRugué \\ Universidad de Girona, España \\ q.brugue@udg.edu \\ Xavier Casademont \\ Universidad de Girona, España \\ Xavier.casademont@udg.edu \\ Judith Gifreu \\ Universidad Autonoma de Barcelona, España \\ Judith.gifreu@uab.cat \\ Oscar Prieto-Flores \\ Universidad de Girona, España \\ oscar.prieto@udg.edu

\section{RESUMEN}

Durante los últimos años ha emergido un renovado interés por los referéndums y las consultas ciudadanas, tanto en ámbitos nacionales como locales. Se trata de formas de democracia directa que han sido poco estudiadas hasta el momento. Este artículo propone un marco conceptual para analizar cinco estudios de caso, experiencias locales que han permitido destacar las fortalezas y las debilidades de las consultas ciudadanas. Las fortalezas se centran en su flexibilidad y en su capacidad ayudar a los gobernantes a tomar decisiones en situaciones difíciles. Las debilidades tienen que ver, sobre todo, con las dificultades de situarlas en un contexto de debate e información pública y, también, con el poco interés que ha logrado despertar entre la ciudadanía.

Palabras clave: Consulta ciudadana, Gobierno local, Información pública, Participación. 


\title{
LOCAL CITIZEN CONSULTATIONS: \\ BETWEEN GOVERNMENT LEGITIMATION AND CITIZEN \\ EMPOWERMENT
}

\begin{abstract}
In recent years, there has been renewed interest in referendums and citizen consultations at both national and local levels. These forms of direct democracy have been little studied so far. This paper proposes a conceptual framework for analyzing five case studies of local experiences that have highlighted the strengths and weaknesses of citizen consultation processes. Their strengths lie mainly in their flexibility and ability to help rulers make decisions in difficult situations while their weaknesses have to do, above all, with the difficulties of situating them in a context of debate and public information and also the limited interest citizens have shown in them.
\end{abstract}

Keywords: Citizen consultation, Local government, Public information, Participation. 


\section{INTRODUCCIÓN}

La democracia no es tan solo uno de los términos más debatidos en la historia del pensamiento político, sino que, además, en el momento actual, conforma uno de los principales retos para el futuro de nuestras sociedades. La teoría política suele referirse a dos grandes momentos democráticos: la democracia de los antiguos (ejemplarizada en el ágora ateniense del siglo $\mathrm{V}$ a. C.) y la democracia de los modernos (que iniciaría su andadura institucional a partir de la Constitución de Filadelfia de 1787) (Barber 2004, Tilly 2010). Hoy, según diversos observadores, podríamos estar asistiendo a un tercer momento democrático (Craig, Kreppel y Kane 2001, Crouch 2004, Urquizu 2016).

En este sentido, ya desde finales de los años ochenta se han ido promoviendo y ensayando nuevas formas de democracia participativa (Creighton 2005). Bajo este epígrafe tan genérico, se ha experimentado con fórmulas que, posteriormente, la academia ha definido por sus componentes deliberativos (Forester 1999, Gutmann y Thompson 2004). Los debates sobre cómo conceptualizar y organizar una democracia deliberativa nos han ocupado hasta los inicios del siglo XXI, mientras que más recientemente han aparecido nuevas prácticas y nuevos debates vinculados a la democracia directa. No se trata únicamente de facilitar cierta influencia de los ciudadanos en las decisiones públicas sino de trasladarles el poder para tomar estas decisiones (Welp y Ordońez 2017). La reciente proliferación de consultas y referéndums, en tanto que expresiones de esta democracia directa, se vincula a una oleada de movilizaciones populares que impugnan el modelo representativo y reclaman un mayor empoderamiento ciudadano. Una impugnación que también conecta con el auge de los nuevos populismos y su voluntad de presentarse como la voz del pueblo frente a los agravios que ha recibido por parte de las instituciones públicas y los partidos políticos tradicionales (Canovan 1999, Haskell 2001, Vallespín y Bascuña 2016).

Este renovado interés por la democracia directa ha entrado en el debate académico (Budge 1999, Leduc 2003, Altman 2010, Green 2010) y, sobre todo, se ha expresado a través de prácticas concretas tan destacadas políticamente como la salida de Gran Bretaña de la Unión Europea (2016), el plebiscito sobre el proceso de paz en Colombia (2016), el referéndum para una eventual modificación constitucional en Italia (2016) o la consulta -no avalada por el régimen jurídico español- sobre la independencia de Cataluña (2017). Y también se ha proyectado este interés por la democracia directa en los gobiernos locales, que han impulsado múltiples y diversas iniciativas de referéndums y consultas ciudadanas (Reynaert 2005, Delwit 
2007, Schiller 2011).

En este contexto, nuestro interés se centra específicamente en acercarnos a algunas de estas experiencia locales de democracia directa; preguntándonos sobre sus orígenes, sobre el modo de desplegarse y sobre los resultados obtenidos. Para avanzar en esta dirección, el artículo se organiza en tres apartados: el primero nos introduce en el debate teórico sobre la democracia directa; el segundo pretende elaborar un marco conceptual apto para el estudio de las consultas locales; $y$, finalmente, dedicamos el tercer apartado, de carácter empírico, a presentar y analizar cinco consultas locales que se han desarrollado recientemente en Cataluña.

\section{DEMOCRACIA DIRECTA: BREVE HISTORIA DE UN INTENSO DEBATE}

Cualquier aproximación teórica a la democracia suele iniciarse con una referencia a su origen etimológico; es decir, a aquella definición que equipara la democracia con el poder del pueblo. Sin embargo, simultáneamente, la literatura especializada nos recuerda que es justamente a partir de aquí cuando aparecen las preguntas relevantes sobre qué significa tener poder, quién forma parte del pueblo o qué implica tomar decisiones de forma democrática. Unas preguntas que han alumbrado un intenso y rico debate.

Así, la primera gran distinción democrática se manifiesta en torno a quién toma las decisiones: el propio pueblo (democracia directa) o sus representantes electos (democracia representativa). La principal diferencia entre ambas alternativas tiene que ver, pues, con la existencia de estructuras de intermediación entre la ciudadanía y el gobierno. De este modo, la primera y más básica definición de democracia directa es aquella que la identifica con una forma de gobernar donde no existen intermediaciones y donde, por lo tanto, es el propio demos quién ejerce el poder.

Ubicados en la modernidad, con unidades política de gran tamaño como los estados o las ciudades, el voto individual sería la forma habitual de ejercer el poder por parte del demos. Su manifestación práctica sería, por lo tanto, el referéndum. En este sentido, acercándonos a una segunda distinción democrática, frente a las dinámicas deliberativas aparece la lógica agregativa; es decir, no se trata únicamente de que las decisiones las tome directamente el pueblo sino que la forma de hacerlo es sumando las preferencias individuales, los votos. Jane Mansbridge (1983) usaba el término "democracia adversarial" para referirse a una formula democrática basada en dos ideas básica: "una persona, un voto" y "la mayoría gana”. 
Este modelo, según la propia autora, puede contraponerse a la concepción democrática de los antiguos, para quienes la mejor forma de tomar decisiones no era el voto sino la palabra; no se trataba de agregar preferencias individuales sino de intercambiar argumentos y buscar respuestas unitarias. Es destacable que, frente al acto solitario del voto moderno, los antiguos proponían las interacciones cara a cara. Y es en este sentido que Giovanni Sartori apunta una definición de democracia directa que, en su sentido fuerte, debe complementar la inexistencia de intermediación con la existencia de relaciones cara a cara entre ciudadanos que deliberan sobre su interés colectivos. Usando sus propias palabras, "la democracia directa es también inmediatez en las interacciones, una relación directa, cara a cara, entre participantes reales” (Sartori 2007: 99)

Así pues, cuando usamos el término democracia directa podemos estar invocando prácticas asamblearias o refrendatarias. Las primeras serían según Sartori- la versión fuerte de la democracia directa. Tal como afirma Verhulst (2006), las asambleas públicas serían la esencia de la democracia. Una forma más propia de las polis de la antigüedad, pero que ha sobrevivido en los cantones suizos, en los town meetings de la costa este norteamericana (Zimmerman 1999; Bowler y Donovan 2000) o, en el caso español, en los Consejos abiertos de los municipios de menos de 100 habitantes (Brugué et al. 2011).

Sin embargo, las prácticas refrendatarias se habrían impuesto durante la modernidad. En este sentido, frente a la seducción que ejercían las asambleas ciudadanas sobre Thomas Jefferson, se impuso la perspectiva de James Madison, quién veía en la representación y la intermediación una forma de doblegar las pasiones e imponer las razones. La democracia liberal -débil, usando el adjetivo que le otorga Barber (2004) - opta por las votaciones porque no confía en la capacidad de los ciudadanos para dominarse, para dialogar y explorar respuestas compartidas a sus problemas colectivos. Prefiere dirimir los conflictos a través del frío silencio que envuelve las urnas o, usando las magistrales palabras de Mansbridge:

Adversarial democracy is the democracy of a cynical society. It replaces common interest with self-interest, the dignity of equal status with the base motives of self-protection, and the communal moments of face-toface council with the isolation of a voting machine (Mansbridge 1983: 72).

Sea como sea, la lógica agregativa o adversarial se impuso durante el momento democrático liberal, de manera que los referéndums se han convertido en la forma habitual de expresar la democracia directa. Frente 
a la aguda crisis de la representación, los defensores de estos mecanismos argumentan que los referéndums facilitan un mayor control de la política por parte de los ciudadanos, así como una asignación compartida de responsabilidades. Las decisiones adoptadas a través de la democracia directa-agregativa ganarían en legitimidad, identificarían mejor la voluntad del pueblo, facilitaría la transparencia y la rendición de cuentas, trasladaría capacidad política a la ciudadanía, y reforzarían sus lazos comunitarios (Kaufman, Büchi y Braun 2007).

Sin embargo, frentes a las oportunidades de fortalecimiento democrático que ofrecen los referéndums, también han aparecido objeciones relevantes. Como ya habíamos mencionado, Giovanni Sartori consideraba el referéndum como una forma solitaria y, por lo tanto, empobrecida de democracia directa. Un empobrecimiento que, de entrada, se traducía en el tránsito desde las dinámicas de suma positiva a las dinámicas de suma cero. Mientras que el gran logro de la democracia se basa en que todos ganamos y perdemos colectivamente, un referéndum -en opinión de Sartori- genera ganadores y perdedores. Una lógica de suma cero que no solo no resuelve los conflictos, sino que incluso, si el referéndum no es gestionado adecuadamente, puede llegar a intensificarlos.

Adicionalmente, Sartori también nos advierte de que las capacidades exigibles a los ciudadanos que votan en un referéndum no son las mismas que deberían ostentar cuando escoge a sus representantes. La democracia representativa reclama opinión pública; es decir, un conocimiento genérico que permite escoger entre opciones poco detalladas y expresar preferencias amplias (Manin 1998). En un referéndum, en cambio, se toma una decisión concreta y, por lo tanto, el votante ha de disponer de un conocimiento más profundo; de una episteme que permita una toma de decisiones sólida. Pero pasar de la opinión al conocimiento no es sencillo, aunque se trata de una condición indispensable para conjurar el potencial manipulador de los referéndums. Usando los provocadores términos de Sartori, "el pueblo tiene derecho a equivocarse, lo cual no justifica que lo induzcamos al error" (2007:106).

\section{DE REFERÉNDUMS Y CONSULTAS: EL PORQUÉ, EL QUÉ Y EL CÓMO}

Tras un breve recorrido por el concepto democracia directa, en este segundo apartado pretendemos construir un marco analítico para el estudio de los referéndums y/o consultas ciudadanas. Con este fin nos planteamos tres interrogantes básicos: ¿¿de qué estamos hablando cuando nos referimos a los referéndums y a las consultas ciudadanas?, ¿cuáles son las razones que 
explican su reciente proliferación (específicamente en el ámbito local)? y ¿cómo se organizan y con qué resultados estos mecanismos democráticos? El qué, el porqué y el cómo de las consultas ciudadanas a nivel local.

\section{¿DE QUÉ ESTAMOS HABLANDO?}

Siguiendo la estela del apartado anterior, un referéndum -y más tarde ya incorporaremos el término consulta ciudadana- es una forma electoral para tomar decisiones, entendiendo que estas se refieren a asuntos políticos específicos y no a la elección de nuestros representantes (Altman 2010, Pindado 2015). A partir de esta definición inicial aparece una multitud de clasificaciones y tipologías en función de su finalidad (de determinación ex ante o de ratificación a posteriori), de quien los convoca (el gobierno o la ciudadanía), de si se promueve de forma voluntaria u obligatoria, o del carácter vinculante o consultivo de sus resultados.

Nos interesa subrayar la distinción en relación a su carácter vinculante o consultivo, pues se trata de un primer aspecto para establecer las diferencias entre los referéndums (vinculantes) y las consultas (no vinculantes). A raíz de la proliferación de consultas, especialmente en el ámbito local, ha aparecido una creciente literatura sobre formas soft de democracia directa: las decisiones se mantienen en manos de los representantes, mientras que se refuerza el derecho de los ciudadanos a ser consultados (Hug 2004, Schiller y Setälä 2012, Fung 2015, Gamper 2015, Jäske 2017).

Además de por su carácter no vinculante, las consultas también se diferenciarían de los referéndums por su voluntad de incidir en decisiones sobre políticas públicas concretas (desbordando las ratificaciones y/o modificaciones legislativas) y por no tener la necesidad de cumplir todos los requisitos formales que suelen acompañar los momentos electorales en la democracia representativa. Así, en una consulta es posible que personas sin condición legal de ciudadanía puedan votar (expandiendo el demos a los empadronados), utilizar el voto electrónico, alargar el período electoral durante varios días o semanas, o relajar la obligación de disponer de órganos específicos de control.

Sin embargo, partiendo de estas tres características específicas de las consultas (no vinculantes, sobre políticas públicas y un marco menos garantista), consideramos que la primera puede ser discutida. A pesar de que a menudo los resultados no sean legalmente vinculantes, lo cierto es que esta afirmación es políticamente difícil de sostener. Una vez que los ciudadanos se han expresado a través del voto, es complicado justificar que los representantes decidan no hacerles caso. Como veremos, este es un 
aspecto que deberemos tener en cuenta a la hora de analizar los resultados de las consultas ciudadanas locales.

\section{¿POR QUÉ TANTO INTERÉS Y EMPEÑO EN PROMOVER ESTOS INSTRUMENTOS DE DEMOCRACIA DIRECTA?}

Ya nos hemos referido a la relación entre el creciente interés por la democracia directa y la crisis de la democracia representativa (SánchezCuenca 2014). Sin embargo, más allá de este contexto general, podemos identificar algunas razones específicas que nos ayuden a comprender su proliferación en el ámbito municipal.

En primer lugar, la creciente capacidad y sofisticación de los ciudadanos se traduciría en un aumento de la demanda por acceder directamente a la toma de decisiones (Dalton 2004). La proximidad con la que operan los gobiernos locales podría intensificar estas demandas.

En segundo lugar, actuando como un espejo, las demandas de participación directa en la toma de decisiones también se explicarían por la pérdida de confianza tanto en las figuras como en las instituciones representativas (Hay 2007). De este modo, a la mayor confianza de los ciudadanos en ellos mismos se añadiría la creciente desconfianza en sus gobernantes.

En tercer lugar, como anticipábamos en la introducción, el crecimiento de fórmulas refrendataria y consultivas conecta con la aparición de nuevos populismos (Hagen 2002). Una versión de esta explicación la encontraríamos en aquello que Morel (2001) definió como la legitimación plebiscitaria; es decir, el uso de la democracia directa como forma de legitimar y fortalecer el propio poder o liderazgo de los gobernantes.

En cuarto lugar, frente a la creciente dificultad de tomar decisiones difíciles sobre políticas públicas complejas por parte de los gobernantes, los referéndums y las consultas no solo buscarían reforzar el poder sino desbloquear su propia obligación de gobernar, de impulsar una acción de gobierno efectiva (Budge 1996, Font y Gómez 2017).

Finalmente, tampoco podemos dejar de mencionar el efecto imitación, pues en un contexto donde proliferan este tipo de experiencias es habitual que los responsables políticos sientan la necesidad de no quedarse rezagados. La moda de los referéndums y las consultas explica también parte de su actual proliferación. 


\section{¿CÓMO ORGANIZAR Y DESPLEGAR UNA CONSULTA CIUDADANA?}

Una consulta ciudadana, igual que un referéndum, exige de unas reglas que regulen su funcionamiento. En realidad, buena parte de su éxito depende de cómo la organización de la consulta potencia sus virtudes y conjura sus debilidades democráticas. Nos referiremos a cuatro aspectos: los requisitos, el proceso de información y deliberación, la organización de la votación y los resultados.

En primer lugar, los requisitos de una consulta son básicos para asegurar un adecuado punto de partida. Estos requisitos pueden referirse al objeto de la consulta, a la quien tiene la iniciativa de situarlo en la agenda y a la formulación de la pregunta. En relación al objeto, las consultas locales deberían ceñirse a las competencias municipales; aunque a menudo tienden a extenderse a ámbitos de carácter simbólico o declarativo. En cualquier caso, parece razonable considerar la importancia de poder implementar la decisión adoptada tras la consulta. En cuanto a la entrada de la agenda, la iniciativa puede ser ciudadana o gubernamental. Normalmente se contemplan ambas posibilidades, aunque en casos como el suizo solo se admitan las consultas de iniciativa ciudadana. Además, según las diversas regulaciones, la entrada en la agenda tiene que cumplir algunos requisitos formales, como un cierto número de firmas de soporte, el apoyo de una parte de Pleno municipal o el seguimiento de ciertos protocolos de control. También nos encontramos, en el caso español, con experiencias que se han desarrollado desde la informalidad. Finalmente, la redacción de la pregunta también es un momento importante, ya que debe evitar posibles ambigüedades y manipulaciones. Suele considerarse que la pregunta debe estar redactada de la forma más simple y clara posible, evitando confusiones e intentando ofrecer respuestas dicotómicas. Una forma de valorar la calidad de la pregunta es asegurar que tanto los partidarios de una opción como los partidarios de la otra están de acuerdo con su formulación.

Un segundo aspecto relevante en la organización de una consulta es aquel que se refiere a la fase previa a la votación. Su importancia entronca con las observaciones de Sartori en relación a la exigencia de una ciudadanía informada y capaz de votar con conocimiento. Para lograrlo se considera fundamental organizar tanto un proceso informativo neutral y veraz como una fase de confrontación de opiniones donde el diálogo proporcione las bases para el conocimiento de las alternativas. El éxito de una consulta, por lo tanto, depende tanto de una fase de información institucional como de la campaña previa donde cada parte pueda defender y argumentar sus posiciones. 
En tercer lugar, la organización de la votación, en tanto que momento culminante de la consulta, debe contemplar diversos detalles logísticos, entre los que destacamos aquellos que se refieren al quién y al cómo de la votación. Mientras que, en los referéndums, los votantes potenciales son aquellos que gozan de la condición jurídica de ciudadanía, en las consultas suele ampliarse este criterio y extenderse hasta las personas mayores de 16 años empadronadas en el municipio. Ambos criterios pueden resultar razonables, pero han de ser definidos con precisión en cada caso. En la práctica, como veremos en alguno de los casos, pueden surgir controversias a la hora de definir un demos donde se proponen votos ponderados (mayor peso a los más informados, por ejemplo) o limitados (solo para las mujeres, cuando se trate de un tema que únicamente sea de su incumbencia).

Por otra parte, en relación al cómo de la votación, también las consultas flexibilizan algunas de las condiciones de los referéndums. Aunque el objetivo de esta flexibilización pueda ser facilitar y aumentar la participación, esto no impide que deban explicitar con el mayor detalle las normas que rigen si el voto puede ser electrónico y/o presencial, los días que durará la votación, o los mecanismos de control y garantías que se utilizarán.

Finalmente, en cuarto lugar, la organización de una consulta debe tener muy claro cómo se gestionarán los resultados alcanzados. En este sentido, más allá de la seguridad en el recuento de los votos y la presentación de los resultados, debería también hacerse explícito la existencia o no de umbrales de participación a partir de los cuáles se validan los resultados, el carácter vinculante o no de la respuesta que resulta vencedora y, también, los métodos de seguimiento que permitan asegurar que se aplican los resultados obtenidos.

\section{DE LA TEORÍA A LA PRÁCTICA: CINCO CONSULTAS CIUDADANAS EN CINCO MUNICIPIOS CATALANES}

En este apartado nos trasladaremos de la teoría a la práctica a partir de cinco consultas ciudadanas celebradas durante los últimos cuatro años en cinco municipios de Cataluña ${ }^{1}$. En este tránsito, sin embargo, no

1 Nos situamos en Cataluña, en primer lugar, por tratarse del ámbito territorial en el que hemos realizado la investigación. Pero también, en segundo lugar, porque en los últimos ańos en Cataluña tanto la retórica como la práctica de la democracia directa ha estado especialmente presente. No solo en razón de su tradición local de experimentar con fórmulas de innovación democrática sino también por un contexto político marcado por el intenso debate en torno un eventual referéndum sobre la independencia de Cataluña respecto España. 
olvidaremos las reflexiones teóricas y el marco conceptual, sino que los usaremos para analizar e interpretar las experiencias. Somos conscientes que cinco casos no nos permiten extrapolar conclusiones, pero sí que nos facilitan una exploración útil para posteriores estudios de mayor alcance. Con estos objetivos en mente, nos referiremos en primer lugar a la elección de los cinco casos, ofreceremos una breve descripción de los mismos y, finalmente, los estudiaremos utilizando los criterios teóricos y analíticos presentados en los apartados anteriores.

\section{Metodología Del ESTUdio EMPÍRICO}

El uso del método de caso tiene importantes limitaciones, especialmente a la hora de generalizar los resultados alcanzados. Sin embargo, su utilización es adecuada cuando se quiere profundizar en una realidad sobre la que no existe suficiente conocimiento previo y, por lo tanto, no disponemos de preguntas precisas para construir una investigación de mayor alcance. Los estudios de caso permiten acercarse a lo desconocido y dejarse sorprender por realidades empíricas a las que nos acercamos a través un marco conceptual, pero sin el estrecho corsé de unas variables muy definidas.

Las consultas ciudadanas en los gobiernos locales españoles son una realidad reciente y desconocida. No han formado parte de una tradición democrática que, en el caso de los ayuntamientos, arranca con las elecciones de 1979 y que, desde entonces, se ha desarrollado a partir de la lógica representativa y de la introducción de experiencias participativas de carácter deliberativo. Hasta hace poco más de cinco años, los referéndums o las consultas fueron excepcionales en el ámbito local. Tampoco disponemos de estudios sobre la reciente proliferación de consultas, especialmente intensa en el contexto catalán. En el libro de Schiller (2011) se revisan las consultas locales en Europa, pero no aparece el caso español. Una ausencia que el propio autor explica por no haber encontrado académicos dedicados a su estudio.

Así pues, en el marco de esta realidad reciente y desconocida hemos optado por el método de los estudios de caso. Para ello, en primer lugar, elaboramos un listado de las consultas celebradas en municipios catalanes durante los últimos cinco años. Debido a la enorme informalidad con la que se han realizado estas experiencias, no existe un registro de las mismas, de manera que elaboramos este primer listado recurriendo a informantes clave y a la prensa (escrita o en red). De esta primera tarea obtuvimos un listado inicial con 14 experiencias (Tabla 1). No se trata de un listado exhaustivo, pero nos ofrecía una perspectiva panorámica para distinguir las diversas experiencias de democracia directa en función del número de 
habitantes del municipio, del nivel de participación alcanzado y, sobre todo, del objeto temático de la consulta.

\section{Tabla 1: Consultas ciudadanas en municipios catalanes 2014-2018}

\begin{tabular}{|c|c|c|c|}
\hline $\begin{array}{l}\text { Municipio y ańo de la } \\
\text { consulta }\end{array}$ & Temática & Participación & $\begin{array}{l}\text { Resultados } \\
\text { (afirmativos) }\end{array}$ \\
\hline $\begin{array}{l}\text { El Figaró i Montmany } \\
\qquad(2014)\end{array}$ & $\begin{array}{l}\text { Consulta para determinar la } \\
\text { posición del ayuntamiento frente al } \\
\text { proceso independentista catalán }\end{array}$ & $31,6 \%$ & $89,2 \%$ \\
\hline Premià de Mar (2014) & $\begin{array}{l}\text { Consulta sobre un cambio } \\
\text { urbanístico y la compra de la } \\
\text { antigua fábrica San Sanpere para } \\
\text { destinarla a usos públicos }\end{array}$ & $8,4 \%$ & $80,2 \%$ \\
\hline Manresa (2014) & $\begin{array}{l}\text { Consulta sobre el futuro del } \\
\text { teatro municipal en el marco de la } \\
\text { ampliación de una plaza central }\end{array}$ & $9 \%$ & $13,3 \%$ \\
\hline L'Esquirol (2014) & $\begin{array}{l}\text { Consulta sobre el cambio de } \\
\text { nombre para el municipio }\end{array}$ & $42 \%$ & $90 \%$ \\
\hline $\begin{array}{c}\text { Comarca Moianès } \\
\text { (2015) }\end{array}$ & $\begin{array}{l}\text { Consulta sobre la creación de la } \\
\text { nueva comarca del Moianès }\end{array}$ & $47,3 \%$ & $80,4 \%$ \\
\hline Rsquera (2015) & $\begin{array}{l}\text { Consulta para la aprobación de un } \\
\text { plan anti-crisis en el municipio }\end{array}$ & $68 \%$ & $56,3 \%$ \\
\hline Bellaterra (2015) & $\begin{array}{l}\text { Consulta sobre la separación del } \\
\text { barrio de Bellaterra del municipio } \\
\text { de Cerdanyola del Vallès. }\end{array}$ & $53,7 \%$ & $94 \%$ \\
\hline Salt (2016) & $\begin{array}{c}\text { Consulta sobre el desarrollo } \\
\text { urbanístico y nuevas actividades en } \\
\text { el sector sur }\end{array}$ & $21,9 \%$ & $87,6 \%$ \\
\hline Olot (2016) & $\begin{array}{c}\text { Consulta sobre la continuidad del } \\
\text { uso de vaquillas en las fiestas del } \\
\text { municipio }\end{array}$ & $18,2 \%$ & $60,1 \%$ \\
\hline Molins de Rei (2016) & $\begin{array}{l}\text { Consulta sobre viabilidad } \\
\text { pública en el marco del proyecto } \\
\text { "Trnasformar la carretera" }\end{array}$ & $8 \%$ & $\begin{array}{c}35,7 \% \\
\text { (opción A) }\end{array}$ \\
\hline $\begin{array}{l}\text { Santa Eulàlia de } \\
\text { Ronsana (2017 }\end{array}$ & $\begin{array}{l}\text { Consulta sobre el método de } \\
\text { recogida de basuras }\end{array}$ & $21,9 \%$ & $\begin{array}{c}78 \% \\
\text { (puerta a puerta) }\end{array}$ \\
\hline Olot (2017) & $\begin{array}{l}\text { Consulta sobre el modelo } \\
\text { urbanístico de una de las vías } \\
\text { principales del municipio }\end{array}$ & $13 \%$ & $\begin{array}{c}61,5 \% \\
\text { (opción A) }\end{array}$ \\
\hline Tortosa (2017) & $\begin{array}{c}\text { Consulta sobre el futuro del } \\
\text { monumento franquista relacionado } \\
\text { con la batalla del Ebro }\end{array}$ & $29,7 \%$ & $\begin{array}{c}68,4 \% \\
\text { (opción A) }\end{array}$ \\
\hline $\begin{array}{l}\text { Ametlla del Vallès } \\
\text { (2018) }\end{array}$ & $\begin{array}{c}\text { Consulta sobre la autorización } \\
\text { para realizar top-less en la piscina } \\
\text { municipal. }\end{array}$ & $12 \%$ & $60,9 \%$ \\
\hline
\end{tabular}

Fuente: Elaboración propia. 
A partir de esta primera perspectiva, la elección de los 5 casos responde, en primer lugar, a la voluntad de centrarnos en municipios de tamańo medio. En Cataluña hay actualmente más de 900 municipios y algo más del $80 \%$ de ellos tienen menos de 5.000 habitantes. En este contexto, nos interesaba evitar tanto las casuísticas excesivamente informales de los micro-municipios como las dinámicas, a menudo muy particulares, de las grandes ciudades. De este modo, los 5 casos elegidos oscilan alrededor de los 30.000, excepto la Atmetlla del Vallès, con cerca de 10.000 habitantes, pero con una dinámica turística que eleva significativamente esta cifra durante el verano. Optar por este tamańo municipal explica porque hemos descartado los casos con porcentajes más elevados de participación, que suelen coincidir con los municipios más pequeños. Por otro lado, como también reflejamos en la Tabla 2, pretendíamos incorporar consultas sobre políticas públicas (Premià de Mar, Salt y Olot) y sobre aspectos de carácter más político-simbólico (Tortosa y la Ametlla del Vallès). Cabe destacar que los tres casos donde se consultaba sobre políticas públicas se refieren a temas urbanísticos.

Tabla 2: Los cinco estudios de caso. Volumen de población y objeto de la consulta

\begin{tabular}{cccc} 
Municipio & $\begin{array}{c}\text { Población } \\
(2016)\end{array}$ & $\begin{array}{c}\text { Objeto consulta: } \\
\text { política pública }\end{array}$ & $\begin{array}{c}\text { Objeto consulta: } \\
\text { político-simbólico }\end{array}$ \\
\hline Premià de Mar (2014) & 27.866 & \\
Salt (2016) & 29.404 & \\
Olot (2016) & 34.000 & \\
Tortosa (2017) & 33.743 & \\
Ametlla del Vallès (2018) & 8.337 & & Fuente: Elaboración propia.
\end{tabular}

Finalmente, para cada caso, aparte de recopilar toda la información disponible (tanto la institucional como la que aparecía en los medios de comunicación), realizamos entre dos y cinco entrevistas semiestructuradas (una a los promotores institucionales de la consulta y otras a agentes que defendían una u otra de las opciones objeto de la consulta). El guión de la entrevista pretendía seguir la lógica del marco conceptual presentado anteriormente, aunque para facilitar la conversación la organizamos a partir de tres grandes bloques: los orígenes de la consulta (el porqué y el qué), su desarrollo (el cómo) y sus resultados. Usaremos estos tres bloques en el apartado de análisis, mientras que dedicamos el siguiente punto a una 
somera presentación de cada uno de los cinco casos.

\section{DESCRIPCIÓN DE LOS CASOS}

Cada uno de los cinco casos requeriría de una contextualización y de una descripción detallada, pero resulta imposible ofrecer toda esta información en un artículo como el que nos ocupa ${ }^{2}$. Por esta razón, hemos seleccionado para cada caso una información básica que presentamos de manera esquemática y resumida. El objetivo, por lo tanto, no es un conocimiento profundo de cada experiencia sino permitir una comprensión adecuada para, en el siguiente apartado, poder seguir la lectura analítica de los casos.

\section{Consulta Can Sanpere en Premià de Mar}

El 8 de octubre de 2014, las personas empadronadas en Premià de Mar mayores de 16 ańos fueron convocadas a una consulta ciudadana que se desarrolló entre el 12 y el 20 de diciembre. El objeto de la consulta era facilitar la adquisición por parte del ayuntamiento y, por tanto, con cargo a los presupuestos del consistorio, de la antigua fábrica Can Sanpere para su futuro uso público. Este edificio era propiedad de un conocido empresario inmobiliario y, a pesar de su estado ruinoso, se encontraba ocupada por un colectivo de jóvenes alternativos. Tras una breve introducción a la situación, la pregunta que se formulaba a la ciudadanía era: “¿Está de acuerdo en que el ayuntamiento expropie los terrenos de la antigua fábrica can Sanpere para destinarlos a zona verde y equipamientos públicos?”.

Esta consultada, realizada de forma prácticamente simultánea a la redacción de la Ley de Consultas Ciudadanas no Refrendatarias 10/2014 de 26 de septiembre, se desarrolló con muchas cautelas y garantías. También pudo verse favorecida por un liderazgo político que logró darle cierta visibilidad y, sobre todo, alcanzar consensos partidistas entorno a la oportunidad de la consulta y a la voluntad de asumir sus resultados como vinculantes. De este modo, el conjunto de las fuerzas políticas municipales aceptó, aunque con algunas reticencias, la convocatoria de la consulta; al tiempo que todas defendían la misma postura favorable a la compra del inmueble. Finalmente, votaron 1.968 personas sobre un censo de 23.401 posibles votantes. Un $8,41 \%$ de participación. El sí se impuso con 1.570 votos, el $80,18 \%$ del total.

2 Puede encontrarse información consultando el proyecto "Democràcia Directa Municipal: Experiències i Criteris de Bones Pràctiques", realizado con financiación del Gobierno de la Generalitat de Catalunya a través del programa DEMOC (referencia 2017DEMOCooog). 


\section{Consulta sobre la reforma urbana del sector sur en Salt}

El 24 de septiembre de 2016 se realizó la consulta ciudadana sobre el desarrollo urbanístico del sector sud del municipio de Salt. Podían votar todas aquellas personas mayores de 16 años empadronadas en la ciudad antes del 31 de julio de 2016. La consulta, promovida por el equipo de gobierno, no era vinculante y se amparó de manera explícita en la Ley 10/2014. Su objetivo era aprobar una modificación del Plan General para dotar a la zona sur de nuevos usos urbanísticos y, de este modo, permitir el establecimiento de centros comerciales y otras actividades de desarrollo económico y urbanístico.

El tema ya había sido controvertido y despertó un intenso debate político. En realidad, la consulta debía ayudar a tomar una decisión en la que existían discrepancias dentro de la coalición de gobierno y, por su puesto, en relación a los partidos de la oposición. Al margen de informaciones adicionales, la papeleta de voto explicaba el contexto en los siguientes términos:

Elayuntamiento deSalt propone a la ciudadanía participar en una cuestión relevante para el municipio como es el posible desarrollo urbanístico de la zona sur, con la posibilidad de implantación de grandes equipamientos comerciales como uno de los principales ejes de la modificación.

A partir de aquí se podía responder sí o no a la modificación del planeamiento urbanístico. Cabe destacar que en la papeleta de votación cada opción -afirmativa o negativa- venía acompañada de diversas razones o de soporte: cuatro argumentos para votar sí y tres vinculados al no. Tras estas especificaciones, la pregunta concreta era: “¿Está de acuerdo en que el ayuntamiento de Salt promueva la modificación del planeamiento del sector sur en estos términos?”.

Se recogieron 4.829 votos (21,9\% de participación) y el sí ganó con un 87,6\%. En julio de 2017 se aprobó la modificación del Plan General en los términos planteados en la consulta, aunque hasta el momento no se han realizado las intervenciones urbanísticas ni se ha materializado la instalación de alguno de los grandes centros comerciales previstos.

\section{Consulta sobre la remodelación del Firal en Olot}

Entre los meses de enero y noviembre de 2016, el ayuntamiento de Olot promovió un proceso de participación para involucrar a la ciudadanía en la transformación urbanística del Firal, un espacio público de alta 
centralidad económica y social. Después de un prologado debate público de aproximadamente un ańo, el proceso culminó en una consulta que se realizó entre el 16 y el 22 de noviembre. Se presentaban tres propuestas y la pregunta rezaba: "Selecciona el proyecto que más te guste para la remodelación del Firal".

Participaron 3.766 personas (un 12,98\% de los 29.175 votantes potenciales) y la propuesta "Tejer, coser y vestir" resultó la vencedora con un $61,50 \%$ de los votos. Sin embargo, este resultado no era determinante, pues suponía un $45 \%$ de la valoración total del procedimiento para la contratación pública del proyecto. El resto dependía de las valoraciones de un jurado de expertos y de la adecuación a ciertos criterios técnicos y presupuestarios. De todas formas, el proyecto más votado también fue el finalmente elegido. En septiembre de 2018 se inauguró el nuevo espacio del Firal con la remodelación ya finalizada.

\section{Consulta sobre el monumento franquista en Tortosa}

El 28 de mayo de 2016 se realizó en Tortosa una consulta ciudadana sobre el mantenimiento o la retirada del monumento levantado durante el Franquismo para conmemorar la batalla del Ebro. Se convocó a la votación a todas aquellas personas mayores de 16 ańos y que antes de enero de 2016 estuvieran empadronadas en el municipio. Este monumento -un monolito en medio del río- había despertado históricamente un polémico debate político que ahora, con la consulta, se pensaba cerrar. La pregunta que se lanzaba a la ciudadanía se redactó en los siguientes términos:

En relación con el monumento a la batalla del Ebro que inauguró el general Franco el año 1966, que cree que debería impulsar el ayuntamiento de Tortosa:

A. Retirarlo y museizarlo para promover la memoria histórica y la paz

B. Mantenerlo, reinterpretarlo y contextualizarlo para promover la memoria histórica y la paz.

La consulta, alimentada por una polémica que se extendió hasta llegar al Parlamento de Cataluña, tuvo un importante impacto mediático y se convirtió en un debate que traspasó los límites del municipio. Dentro del consistorio, las posiciones también eran diversas y se expresaban en notables tensiones entre el gobierno y la oposición, así como también en el interior de los propios grupos políticos. Votaron 8.464 personas sobre un censo de $28.466(29,73 \%)$ y se impuso la opción B con 5.755 votos $(67,99 \%)$. 
Consulta sobre el top-less en las piscinas municipales en la Ametlla del Vallès

Entre el 25 de mayo y el 10 de junio de 2018, las mujeres mayores de 16 años empadronadas en la Ametlla del Vallès pudieron participar en una consulta, declarada vinculante por el equipo de gobierno, sobre la posibilidad de hacer top-less en las piscinas municipales. La votación era únicamente electrónica y en la papeleta se planteaba la siguiente pregunta: “ ¿Ha de modificarse el reglamento de uso para permitir hacer top-less en las piscinas de verano de los equipamientos públicos de Ca l'Arenys y Can Camp en la Atmetlla del Vallès?”.

A pesar de la presencia mediática de una consulta que -debido a su temática- atrajo la atención de los medios nacionales, solo participaron en la consulta 379 mujeres (12\% de participación), de las cuáles 231 votaron sí a la posibilidad de hacer top-less $(60,9 \%)$. Pocas semanas después de finalizar la votación, se modificó la normativa de las piscinas municipales y ya durante el mismo verano de 2018 fue posible hacer top-less en estos equipamientos públicos.

\section{ANÁlisis de las CONSUlTas CIUDADANAS}

Después de acercarnos de manera muy sintética a los cinco casos empíricos, en este apartado pretendemos compararlos y analizarlos. Para ellos, como ya hemos anticipado, usaremos el debate teórico y el marco conceptual presentado anteriormente.

Antes de entrar en este análisis, sin embargo, podemos afirmar que los cinco casos escogidos comparten la definición de consulta ciudadana que hemos apuntado anteriormente. Así pues, se trata de experiencias de democracia directa donde se traslada la capacidad de decisión (sobre aspectos no legislativos) a través del voto de los ciudadanos. Además, al tratarse de consultas y no de referéndums, se han permitido votaciones tanto presenciales como electrónicas, en algunos casos se han concentrado la votación en un día y en otros se han dilatado durante dos semanas, y los votantes potenciales no se han definido a través de la condición jurídica de ciudadanía, sino que se ha ampliado el demos para incluir a los mayores de 16 ańos empadronados en el municipio.

En uno de los casos, como comentaremos posteriormente, se ha restringido el voto y solo han podido ejercerlo las mujeres. Los resultados de la consulta se consideraban vinculantes en 2 casos, mientras que en los otros tres se asumía su carácter estrictamente consultivo -aunque 
solo fuera formalmente. Finalmente, en cuatro de los cinco casos, sus promotores afirman haberse acogido a la Ley de Consultas Ciudadanas no Refrendatarias 10/2014.

\section{LOS ORÍGENES: EL PORQUÉ DE UNA CONSULTA CIUDADANA}

A partir de las aportaciones de la literatura especializada, habíamos identificado cinco razones para explicar el porqué de la actual proliferación de las consultas ciudadanas locales: 1) la mayor capacidad y sofisticación de la ciudadanía; 2) el descrédito y la pérdida de confianza en los gobernantes; 3) la búsqueda de legitimación plebiscitarias asociada a la lógica populista; 4) la necesidad de reforzar el poder para poder tomar decisiones efectivas en entornos cada vez más complejos; y 5) el efecto moda. Hemos de preguntarnos, por lo tanto, hasta qué punto cada una de estas cinco explicaciones se encuentra en el origen de nuestros casos empíricos. Una primer respuesta, simple y esquemática, es la que recogemos en la Tabla 3.

Tabla 3: Las razones para impulsar las consultas ciudadanas

$\begin{array}{lcccc}\text { Capacidad de } & \begin{array}{c}\text { Desconfianza } \\ \text { la ciudadanía el gobierno }\end{array} & \begin{array}{c}\text { Legitimación } \\ \text { plebiscitaria }\end{array} & \begin{array}{c}\text { Poder para } \\ \text { tomar } \\ \text { decisiones }\end{array} & \begin{array}{c}\text { Efecto } \\ \text { moda }\end{array} \\ \end{array}$

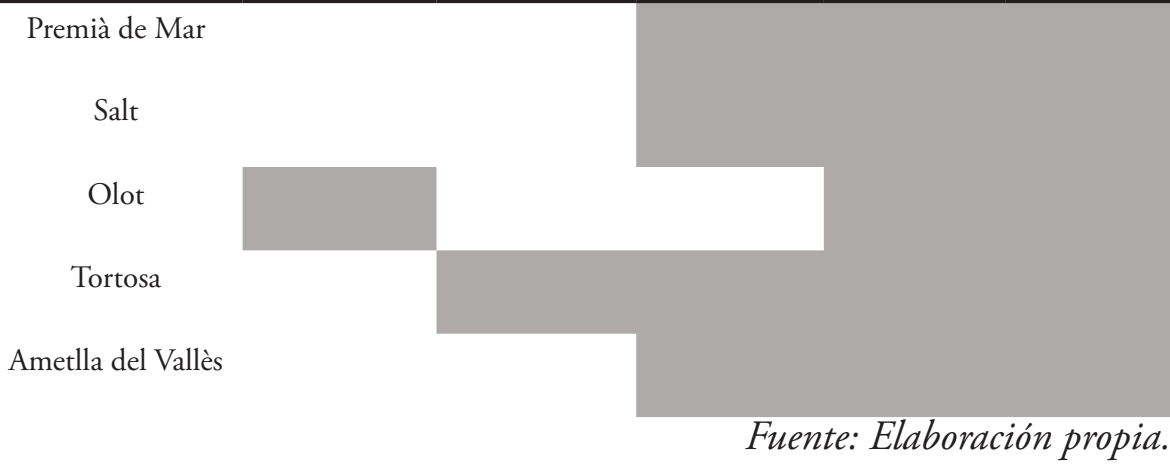

La lectura de esta tabla desafía algunos de los argumentos que de manera algo mecánica venimos usando para explicar la aparición de estos instrumentos de democracia directa. En este sentido, los argumentos más utilizados -tanto en la literatura académica como en el propio debate político- suelen referirse a lo que podrían ser las dos caras de una misma moneda: el empoderamiento de una ciudadanía cada vez más capacitada y la desafección hacia unos gobernantes y unas instituciones crecientemente desacreditadas (Hay 2007). Sin embargo, en ninguno de los casos estas razones aparecen como desencadenantes de las consultas.

Únicamente en Olot encontramos una referencia explícita al poder de 
la ciudadanía y a la necesidad de incorporarla en el proceso de toma de decisiones. Una referencia que, según explican los propios entrevistados, se vincula a una experiencia anterior donde aparecieron serios problemas con una transformación urbanística que no contó con el soporte y la complicidad de la población. De forma parecida, el debate político en Tortosa se encontraba atrapado en una dinámica de desconfianza institucional, en parte motivada por la fuerte simbología del tema objeto de la disputa. De esta desconfianza acabó emergiendo la oportunidad de la consulta.

Por otra parte, en los otros tres casos se nos traslada de forma explícita que nos encontrábamos ante experiencias top-down; donde los orígenes no se encuentran ni en la fuerza ciudadana ni en la debilidad institucional sino, más bien, en el propio empeño de los gobernantes. En realidad, y esta ha sido una constatación hasta cierto punto sorprendente, en todos los ejemplos estudiados los actores sociales más implicados en la consulta se mostraban contrarios a la misma. En unos casos esta posición se explicaba por la negativa a someter a votación temas que ya disponían de cauces legales y/o políticos (Premià de Mar, Salt y Olot) y en otros por preguntar sobre temas que afectan a derechos humanos (Tortosa, Ametlla del Vallès). Como puede observarse, la primera explicación afecta a las consultas sobre políticas públicas, mientras la segunda a las que abordan aspectos políticosimbólicos.

Los otros tres argumentos teóricos aparecen como dominantes en los orígenes de las cinco consultas de nuestra muestra. La lógica populista -que hemos definido como legitimación plebiscitaria (Green 2010) - se encuentra presente de forma clara en cuatro de los cinco casos. Una lógica que se manifiesta a través de reconocer en los inicios de la consulta la oportunidad de trasladar a los ciudadanos una decisión que, en realidad, el equipo de gobierno no puede o no quiere tomar. En Premià de Mar se nos explicaba cómo la consulta se utilizó para trasladar el tema desde un escenario judicial (donde la probabilidad de que el empresario inmobiliario impusiera sus intereses era mayor) a un escenario político (donde, con el apoyo de la ciudadanía, podría ganar la opción del equipo de gobierno). Además, este cambio de escenario contaba con la fuerza de una consulta (plebiscitaria) donde, en realidad, se daba a escoger entre el interés privado (votar no) o el interés colectivo (votar sí). De modo parecido, el punto de partida en Salt era un desacuerdo en la coalición de gobierno sobre el modelo de desarrollo económico y urbanístico. La consulta desbloqueó este desacuerdo y legitimó al gobierno para impulsar un proyecto avalado plebiscitariamente, incluso cuando no era compartido por alguna de las formaciones políticas. Una situación muy similar la encontramos en Tortosa, 
mientras que en la Ametlla del Vallès se reconoce que, frente a un conflicto que se fue envenenando, la consulta fue una salida; una forma de trasladar la decisión a la ciudadanía. Únicamente en Olot no aparece con claridad esta referencia plebiscitaria, pues se trata de una consulta enmarcada en un proceso participativo de mayor alcance y donde, por lo tanto, la lógica del voto convive con la deliberación pública, con valoraciones técnicas y con ciertos criterios previos expresados desde las instituciones representativas.

Finalmente, no encontramos excepciones a la hora de considerar que tanto la necesidad de tomar decisiones efectivas como el efecto moda se encuentran en los orígenes de las cinco consultas. En todos los casos se argumenta como la consulta contribuirá a la implementación efectiva de la decisión, de la misma manera que también en los cinco ejemplos se apela continuamente a una apuesta genérica por la democracia participativa. El primer aspecto es destacable por su vínculo con las teorías relacionadas con la complejidad y el giro deliberativo de las políticas públicas (Forester 1999, Fischer 2003), mientras que el segundo tiene que ver con el efecto moda (Cooke y Kothari 2001). Durante las últimas décadas, la invocación participativa ha sido recurrente en el mundo local y, de forma más reciente, esta se ha trasladado a las prácticas de democracia directa. Una moda que se enmarca en los movimientos sociales que claman por la desintermediación de la política (Blanco y Gomà 2016), pero también en las especificidades del contexto catalán. En Cataluña, el efecto moda no se genera únicamente a partir de la comparación democrática entre ayuntamientos, sino también en un contexto donde la reivindicación de un referéndum para resolver el problema de la relación con Cataluña ocupa un lugar destacado en la agenda política.

Podemos concluir este apartado destacando cuatro puntos:

- En los orígenes de estas consultas ciudadanas se encuentra un problema complejo; un conflicto polémico y una situación delicada que incomoda a los gobiernos que deberían abordarla.

- $\quad$ Frente a este problema aparece una voluntad y un liderazgo político que, amparándose en el consenso que despierta la participación ciudadana (efecto moda), propone una salida a través de la consulta. Una propuesta que siempre es institucional (top-down) y que suele ser consensuada o que, como mínimo, precisamente debido a su retórica democrática, no genera una oposición explícita y fuerte.

- Al trasladar la respuesta al conflicto a la ciudadanía, la consulta actúa como un factor que desbloquea y desencalla, facilitando una decisión que no obliga a mojarse a los gobernantes y que, simultáneamente, dispone de una legitimidad reforzada. 
- Sorprendentemente, las reticencias más explícitas las ponen de manifiesto los actores sociales más implicados. Frente al inevitable consenso democrático, algunas voces consideran que no siempre es lícito resolver los problemas a través de consultas sobre temas que deberían ser responsabilidad de los gobernantes (Olot), que disponen de un marco legal ya aprobado (Tortosa) o que afectan la libertad individual de las personas (Ametlla del Vallès).

\section{El DESARROlLO: El CÓMO DE LAS CONSUlTAS CIUDADANAS}

El cómo es una dimensión muy relevante a la hora de entender tanto el desarrollo como los resultados de las consultas ciudadanas. En el marco conceptual identificábamos diversas variables a tomar en consideración a la hora de organizar y desplegar una consulta ciudadana. Empezamos, como en el apartado anterior, resumiendo en la Tabla 4 las principales características de este cómo en cada una de las experiencias analizadas.

\section{Tabla 4: La organización de las consultas}

\begin{tabular}{|c|c|c|c|c|c|}
\hline & $\begin{array}{c}\text { Premià de } \\
\text { Mar }\end{array}$ & Salt & Olot & Tortosa & $\begin{array}{c}\text { Ametlla del } \\
\text { Vallès }\end{array}$ \\
\hline $\begin{array}{l}\text { Contenido } \\
\text { competencia } \\
\text { municipal }\end{array}$ & Sí & Sí & Sí & No & Sí \\
\hline $\begin{array}{c}\text { Requisito } \\
\text { entrada }\end{array}$ & Institucional & Institucional & Institucional & Institucional & Institucional \\
\hline $\begin{array}{c}\text { Requisito } \\
\text { formulación }\end{array}$ & Pregunta clara & $\begin{array}{l}\text { Pregunta } \\
\text { compleja }\end{array}$ & Pregunta clara & $\begin{array}{l}\text { Pregunta } \\
\text { compleja }\end{array}$ & Pregunta clara \\
\hline Información & Alta & Alta & Alta & Mediana & Baja \\
\hline Campaña & Media & Media & Media & Media-Baja & Inexistente \\
\hline Votantes & $\begin{array}{c}\text { Personas } \\
\text { empadronadas } \\
\text { mayores de } 16 \\
\text { años }\end{array}$ & $\begin{array}{c}\text { Personas } \\
\text { empadronadas } \\
\text { mayores de } 16 \\
\text { años }\end{array}$ & $\begin{array}{c}\text { Personas } \\
\text { empadronadas } \\
\text { mayores de } 16 \\
\text { años }\end{array}$ & $\begin{array}{c}\text { Personas } \\
\text { empadronadas } \\
\text { mayores de } 16 \\
\text { años }\end{array}$ & $\begin{array}{c}\text { Mujeres } \\
\text { empadronadas } \\
\text { mayores de } 16 \\
\text { ańos }\end{array}$ \\
\hline $\begin{array}{c}\text { Forma de } \\
\text { votar }\end{array}$ & $\begin{array}{l}\text { Presencial y } \\
\text { electrónica }\end{array}$ & Presencial & Electrónica & Presencial & Electrónica \\
\hline $\begin{array}{c}\text { Período de } \\
\text { votación }\end{array}$ & 9 días & 1 día & 7 días & 1 día & 15 días \\
\hline $\begin{array}{l}\text { Sistema de } \\
\text { garantías }\end{array}$ & Alto & Alto & Alto & Medio & Bajo \\
\hline
\end{tabular}

Fuente: Elaboración propia.

Las primeras tres filas de la tabla se refieren a los requisitos de una consulta. El primero de ellos -el requisito de contenido- señala la importancia de que el objeto de la consulta sea de competencia municipal. De los cinco 
casos de nuestra muestra, en cuatro la votación puede conectarse con una decisión que el gobierno local es competente para adoptar. En Tortosa, en cambio, la decisión sobre el monumento no compete al ayuntamiento, sino que se enmarca en la legislación estatal y autonómica sobre la memoria histórica, así como en la capacidad de actuar en el espacio hídrico reservada a la Confederación Hidrográfica del Ebro. Esta circunstancia explica, al menos en parte, porque transcurridos dos años desde que se realizó la votación, siguen sin implementarse sus resultados.

El segundo requisito ya ha sido comentado en el apartado anterior al constatar cómo, en todos los casos, la iniciativa consultiva se sitúa en el nivel institucional y la adopta el equipo de gobierno. También en todos los casos esta iniciativa cuenta, por un lado, con cierta indiferencia social -a la que nos referiremos más adelante- $y$, por otro lado, de un asentimiento más o menos entusiasta de la oposición. En general, no detectamos un soporte fuerte por parte de la oposición, quienes suelen argumentar en contra de la elección del tema objeto de consulta, aunque la fuerza de arrastre que supone la apuesta por la democracia participativa acaba traduciéndose en un soporte genérico. Estas reticencias aparecen en las entrevistas en los cinco casos, argumentando que se trata de una salida que evita la toma de decisiones (Ametlla del Vallès), de un tema sobre el cuál no se dispone de competencias (Tortosa), de una política pública que reclama más democracia deliberativa que directa (Olot), de un asunto que presenta aristas legales (Premià de Mar) o de una decisión excesivamente compleja y que, en su abordaje dicotómico, puede generar confusiones y ambigüedades (Salt).

En relación al tercer requisito de formulación, la redacción de la pregunta es clara y acordada en tres de los cinco casos. De este modo, en las consultas de Premià de Mar, Olot y la Ametlla del Vallès la pregunta que se plantea es sencilla y no induce al error. En Premià y la Ametlla se traslada a la ciudadanía un interrogante que se responde de forma dicotómica (sí o no a una intervención municipal) y que, además, no induce a ninguna duda razonable sobre cómo convertir el resultado de la votación en una acción concreta (modificar el reglamento de las piscinas municipales o expropiar los terrenos de la antigua fábrica Can Sanpere). En el caso de Olot se presentan tres proyectos de remodelación del espacio urbano y se pide a la ciudadanía que elija aquel que más le gusta.

En los casos de Tortosa y Salt, a pesar de los esfuerzos técnicos, las preguntas que se someten a votación son más complejas y pueden inducir ciertas ambigüedades. En Tortosa estas ambigüedades se relacionan tanto a la indefinición sobre el papel del ayuntamiento en el asunto del 
monumento franquista como al hecho de no optar entre monumento sí o monumento no, sino a algo más sofisticado como a elegir entre "mantenerlo, reinterpretarlo y contextualizarlo" o "retirarlo y museizarlo". Una redacción que, además, genera alguna confusión porque en ambos casos se comparte la idea de "promover la memoria histórica y de la paz" y porque no se traduce de forma clara en una actuación concreta. En el caso de Salt las dificultades a la hora de interpretar la pregunta derivan tanto de la complejidad del propio tema como de una formulación donde el votante debe bucear en una introducción jurídica y distinguir entre dos alternativas que se le presentan acompañadas de siete argumentos de soporte. Además, tal como nos han explicado las personas entrevistadas, la sofisticación del debate se vio superada por una formula popularizada $-\mathrm{y}$, simultáneamente, incierta- que traducía las opciones entre modelos de desarrollo económico al hecho de pronunciarse sobre si se querría o no la instalación de una gran instalación de una conocida firma comercial. Esta deriva del debate pudo generar confusiones e, incluso, explicar ciertas prácticas de inducción del voto. No es de extrañar que fuera en estos dos casos donde la polémica política fuera más intensa.

En cuanto a la importante fase previa al momento de la votación, destacábamos la necesidad de acompañar la consulta tanto de una estrategia informativa (unidireccional) como de una campaña de debate público (bidireccional). Excepto en el caso de la Ametlla del Vallès, donde se reconoce -por las propias especificidades del objeto de la consultaque no se generó ninguna información ni se promovió ningún debate público, en los demás casos se realizaron esfuerzos informativos y, en menor medida, deliberativos. Sin embargo, en todos los casos -quizá con la excepción de Olot- se pone de manifiesto una notable decepción con los resultados alcanzados. Por una parte, como nos expusieron para el caso de Premià de Mar, se reconocen los límites de estas estrategias comunicativas cuando la consulta es una iniciativa institucional y no social. La ciudadanía no la percibe como algo suyo y tiende a desentenderse de la consulta. La indiferencia social a la que nos referíamos anteriormente. Por otra parte, la complejidad de algunas temáticas -como el modelo de desarrollo económico y urbanístico de la zona sur de Salt- propició un apasionado debate político que, en cambio, generó cierta confusión y distanciamiento en parte de la población. Se movilizó -nos relataba uno de los entrevistados- a los partidos políticos, pero no a las entidades sociales. Algo parecido sucedió en Tortosa, donde, además, el debate parecía más activo en el Parlamento de Catalunya que en el propio municipio. Según algunas de las opiniones recabadas, se acabó votando más como respuesta a las inferencias externas que como resultado del debate en el interior del propio municipio. 
En relación con los aspectos logísticos, detectamos una amplia variación tanto en las formas (presenciales o electrónicas) como en la duración de la votación (entre un día y dos semanas). También encontramos diferencias entre aquellos casos donde únicamente se podía votar físicamente en el ayuntamiento y aquellos otros donde se habilitaron diferentes emplazamientos para facilitar la proximidad de los votantes. Por ejemplo, en el caso de Premià de Mar se podía votar en la biblioteca, en el centro cívico, en la escuela de música, en el edificio del Gas y en el pabellón de deportes. Esta variabilidad nos muestra la flexibilidad de las consultas ciudadanas que, a diferencia de lo que ocurre con los referéndums, son capaces de adaptarse a situaciones y coyunturas particulares. Además, otra vez con la excepción del caso de la Ametlla del Vallès, en todas las experiencias se manifiesta una intensa preocupación por los mecanismos de control y las garantías que redundarán en la legitimidad de los resultados alcanzados. Se considera muy importante asegurar con la máxima nitidez la seguridad y la neutralidad del proceso electoral $y$, aunque no cuenten con una normativa tan estricta como los referéndums, las personas entrevistadas han mostrado un especial interés en subrayar los esfuerzos realizados en esta dirección. Estos esfuerzos han sido especialmente intensos en Premià de Mar, donde se pone en marcha un complicado sistema de garantías (comisión de control ciudadano, comisión de seguimiento y comité de consultas ciudadanas), pero aparece también en los casos de Salt, Olot y Tortosa.

Finalmente, en relación al quién puede votar-al demos- en cuatro de los cinco casos la respuesta es clara y sencilla: todas aquellas personas mayores de 16 años que estuvieran empadronadas en el municipio antes de una determinada fecha. La idea es involucrar en la política local tanto a los jóvenes como a aquellas personas que -en municipios con altos porcentajes de inmigración, especialmente en el caso de Salt- son residentes sin la condición legal de ciudadanía. Sin embargo, tanto en Salt como en Olot y en Premià, se nos comenta de forma explícita que la participación fue especialmente baja entre los más jóvenes y entre la población inmigrante. Incorporarles a la consulta ciudadana no habría servido para movilizarlos políticamente.

El caso de la Ametlla del Vallès merece algunos comentarios adicionales, ya que, después de un polémico debate, se optó por restringir el voto a las mujeres mayores de 16 años empadronadas en el municipio. Inicialmente, incluso, se había barajado la posibilidad, después descartada, de una restricción mayor al limitar el derecho a voto a las mujeres mayores de 16 años y que fueran usuarias con carnet de la piscina municipal. En cualquier caso, la restricción de género se justificaba por tratarse de un tema que únicamente les concernía a ellas: su propio cuerpo. Esta fue una decisión 
controvertida y, antes de adoptarse, fue consultada con diferentes instancias supralocales como el Instituto Catalán para la Igualdad de Género y el Defensor del Pueblo. Una decisión que, más allá de la casuística del caso, tiene importantes consecuencias para el debate sobre si es o no posible realizar consultas orientadas únicamente a una parte, a un subconjunto de lo que habitualmente consideramos el demos. Estas restricciones pueden justificarse en base a defender los intereses de aquel colectivo directamente afectado por la decisión, pero rompe el principio de "una persona, un voto" y abre una auténtica caja de Pandora sobre cuando aplicar estas restricciones o cuando considerar que un tema afecta al conjunto de la población. En realidad, como comentábamos anteriormente, solo pudieron votar las mujeres, pero se podía haber optado por limitar el voto a las socias de la piscina municipal. Este problema también se planteó en Olot, donde se insinuó -aunque finalmente se descartó- la idea de dar un mayor peso a los vecinos cercanos al área objeto de la intervención urbanística. En otro caso que no ha sido incluido en este estudio, pero al que también hemos tenido acceso, el voto se ponderaba de modo que el valor del voto de aquellos ciudadanos que habían asistido a las sesiones informativas organizadas por el ayuntamiento valía el doble que el de aquellos que no habían asistido. El objetivo era fomentar y valorar el voto informado, aunque esto implicara poner en cuestión la regla de "una persona, un voto".

En definitiva, podemos resumir también en cuatro puntos los aspectos más destacados de este apartado dedicado a la organización y el desarrollo de las consultas ciudadanas:

- En las consultas analizadas se cumplen de forma apropiada los requisitos de contenido (excepto en el caso de Tortosa) y de entrada (siempre top-down), mientras que en 2 de los 5 casos el requisito de formulación es como mínimo objetable.

- A pesar de la preocupación por las fases previas de información institucional y campaña de debate (subrayada en todos los casos excepto en la Ametlla del Vallès), sus resultados se valoran muy negativamente. Se trata de una asignatura pendiente, pero se reconoce muy difícil de superar mientras las consultas sean el resultado de iniciativas gubernamentales y, consecuentemente, no suelen despertar más que indiferencia entre la ciudadanía.

- Hemos detectado una importante variabilidad y, por lo tanto, flexibilidad en los aspectos logísticos de las consultas. Sin menospreciar la importancia de los controles y las garantías, parece que estas consultas son capaces de adaptarse a situaciones y problemas específicos.

- $\quad$ En relación al quién puede votar, por una parte, vemos como -de 
manera muy consensuada- las consultas lo amplían hacia las franjas de residentes empadronados y jóvenes de entre 16 y 18 años. Por otra parte -y ahora en el marco de un debate problemático- también vemos algunos intentos de dirigirse a subconjuntos del demos, focalizando a los votantes directamente afectados por el objeto de la consulta pero violando el principio clásico de "una persona, un voto".

\section{El RESUlTAdo DE LAS CONSUltas}

Más allá de los resultados numéricos que arrojan las urnas y que ya hemos anticipado en el apartado descriptivo, una consulta ciudadana es una forma democrática de tomar decisiones. Deberíamos, pues, esperar unos resultados que se expresen en estos términos. Unos términos que deberían traducirse en la capacidad de abordar determinados problemas, de hacerlo a través de un proceso democrático, de ofrecer respuestas dotadas de suficiente legitimidad y de, finalmente, lograr la efectividad de unas decisiones que se implementaran en función de los resultados de la consulta. Hemos resumido estos argumentos en la Tabla 5, entendiendo que los resultados que ahora estamos analizando no son los porcentajes concretos de cada caso sino las valoraciones que hacen de ellos sus propios protagonistas.

Tabla 5: Valorando los resultados de las consultas

Valoraciones positivas

Problemas abordados $\begin{gathered}\text { Capacidad para abordar problemas } \\ \text { complejos y polémicos }\end{gathered}$

Proceso de resolución

Procesos flexibles y nítidos: no se han generado problemas logísticos

Legitimidad democrática

Efectividad implementación

\section{Participación alta (Salt, Olot y} Tortosa)

Referencias positivas al hecho de promover experiencias de profundización democrática

No ha habido sorpresas en relación a los resultados esperados por la institución

Implementación efectiva de los resultados: Olot y Ametlla del Vallès
Valoraciones negativas

Problemas que interesan más a los gobernantes que a los ciudadanos

Las fases de información y deliberación no han generado los resultados esperados.

Participación baja (Premià de Mar y Ametlla del Vallès)

Sesgos participativos que afectan de manera especial de determinados colectivos

Ausencia de aplicación de los resultados de la votación (Premià de Mar, Salt $\mathrm{y}$ Tortosa)

Fuente: Elaboración propia. 
Como puede observarse, en la tabla -a diferencia de los anteriores- no distinguimos entre los casos sino entre las valoraciones positivas y negativas asociadas a las consultas. Esta presentación nos permite presentar una visión panorámica de aquellos aspectos mejor y peor valorados por los protagonistas de los cinco casos de nuestra muestra.

Así, en primer lugar, se destacan aspectos positivos vinculados a las cuatro dimensiones que hemos establecido para valorar los resultados de las consultas: se nos presentan como una buena fórmula para resolver problemas que generan polémica, se han desarrollado con flexibilidad y sin provocar tensiones organizativas destacables, en algunos casos (tres sobre cinco) han alcanzado una participación notable, se presentan como experiencias que encajan y ponen en valor el discurso sobre el empoderamiento democrático, no se han traducido en decisiones que hayan chocado con los intereses de la institución promotora y, finalmente, su implementación ha sido efectiva (aunque solo en dos de los cinco casos). Frente a estos aspectos positivos, aparecen también sus contrapartes.

En este sentido, en las entrevistas se nos recuerda que a menudo los problemas abordados responden más a los intereses de los gobernantes que a los delaciudadanía, quelas fases previas-y muy importantes-de información y deliberación no logran los objetivos mínimos e imprescindibles, que los niveles de participación a menudo son excesivamente bajos (2/5) y muy frecuentemente sesgados y que, finalmente, en tres de los cinco casos los resultados siguen sin haberse implementado después de dos o tres años de finalizar la consulta.

La enumeración de estos pros y contras nos sugiere que los aspectos positivos se concentran en el corto plazo, mientras que en el largo plazo los resultados se aprecian con más matices. Las consultas producen una satisfacción inmediata en la medida que no solo solucionan problemas concretos y difíciles de abordar, sino que, además, se asientan en el confortable discurso del fortalecimiento democrático y la participación ciudadana. Además, como circulan por los carriles de un asentimiento general -aunque no entusiasta-, su desarrollo no parece generar problemas prácticos importantes.

Estas satisfacciones del corto plazo tienden a difuminarse cuando la perspectiva temporal se amplia. En ese momento, como reconocen los propios promotores de las consultas, parece que el problema no siempre ha quedado tan resuelto como inicialmente se creía, al tiempo que las limitaciones y los sesgos participativos ensombrecen la transformación democrática que prometían. 
Esta asimetría entre las valoraciones a corto y a largo plazo puede tener que ver con unas consultas que son utilizadas instrumentalmente por los gobernantes pero que, en realidad, no abordan los problemas de fondo de los ciudadanos. Las consultas tendrían un carácter más teatral que real, proporcionando un momento de ilusión democrática que luego se vería matizado tanto por sus propios límites (baja participación y ausencia de debate público) como por su escasa -incluso nula- incidencia en el día a día de las comunidades. El efecto moda, al que ya nos hemos referido anteriormente, dotaría a las consultas de cierta impostura; una acción llamativa, pero de corto recorrido.

Aunque de forma menos explícita, esta idea aparece en las percepciones de una buena parte de nuestros entrevistados. Incluso más, son los propios protagonistas de estas iniciativas quienes, tras su primera valoración positiva, reconocen los límites y proponen algunos retos de futuro. En este sentido, no es de extrañar que, frente a los retos de superar la instrumentalización gubernamental y asegurar la aplicación de los resultados, se nos lanzaran tres propuestas concretas: 1) promover las consultas convocadas por iniciativa ciudadana (bottom-up); 2) articular un modelo de organización independiente (no institucional) de las consultas; y, finalmente, 3) impulsar comisiones de seguimiento y mecanismos sancionadores cuando no se cumplan los resultados de la consulta. Las tres propuestas pretenden situar el interés ciudadano en el centro de la consulta. Si no se logra este objetivo, las consultas -como ha sucedido con otros mecanismos de participación ciudadana- podrían convertirse en juguetes en manos de los gobernantes, pero con poca capacidad para interesar a aquellos que, de hecho, están más interesados en la realidad que en el juego.

\section{CONCLUSIONES}

No es la intención de este apartado final resumir los contenidos de las páginas precedentes. Pretendemos, en cambio, en primer lugar, establecer una relación entre los resultados de las consultas (valorativos, no numéricos) y sus orígenes y su desarrollo (que actuarían como variables explicativas). Una relación que, dado que trabajamos únicamente con cinco casos, no podemos aspirar a generalizar, pero sí puede ofrecernos pistas para futuras hipótesis de trabajo. Y, en segundo lugar, ofrecer algunas ideas para un uso satisfactorio de las consultas, tanto en el corto como en el largo plazo.

En primer lugar, si intentamos tratar el éxito y la satisfacción generada por las consultas como si fuera la variable a explicar, entonces -tal como hemos visto en el apartado anterior- deberíamos distinguir entre las valoraciones a corto y a largo plazo. Las primeras son satisfactorias en los 5 
casos estudiados, mientras que las segundas solo se manifiestan con cierta claridad en la consulta sobre el Firal en Olot. Tanto en Premià como en Salt y en Tortosa, la no implementación de los resultados de la consulta ha dejado un gusto amargo entre sus promotores, mientras que el caso de la Ametlla del Vallès es demasiado reciente para valorarlo a largo plazo.

Nos interesará, por lo tanto, destacar aquellas especificidades del caso de Olot que pudiéramos usar como futuras hipótesis de trabajo. En este sentido, aunque quizá lo expresemos de un modo quizá excesivamente provocador, lo que parece caracterizar la consulta de Olot es que es la menos consulta de las 5 . Es decir, aparece como menos consulta, aunque en realidad, para ser más precisos, lo que sucede es que se trata del único caso donde -en el marco de un proceso participativo más largo- nos encontramos con una fase previa de información y debate más intensa y trabajada. La fase de votación es similar a los otros cuatro casos, pero la pre-votación le resta el protagonismo obtenido en el resto de experiencias analizadas.

Así, mientras en las otras cuatro consultas se pretendía resolver un problema puntual y envenenado con una solución excepcional, en Olot se aborda una política pública y se aborda a través de un complejo proceso que combina la iniciativa gubernamental, los criterios técnicos y la deliberación democrática. Solo en último término se convocó la consulta ciudadana. Este largo recorrido permitió trabajar las fases previas de información y deliberación, al tiempo que situaba la consulta en una situación que no era simplemente la de salvar al equipo de gobierno de una situación delicada. Ciertamente, en los orígenes de la consulta se encuentra una experiencia anterior desafortunada; pero también, observando la otra cara de la moneda, un aprendizaje que explica la opción por incorporar a la ciudadanía en la planificación urbanista. Podríamos concluir, al menos en términos de hipótesis para contrastar en posteriores estudios más sistemáticos, que el éxito de una consulta depende de su capacidad para evitar ser una respuesta puntual a las urgencias institucionales y convertirse en un elemento más de un proceso de construcción de políticas públicas.

Esta hipótesis nos lleva, en segundo lugar, a anticipar dos recomendaciones fundamentales en torno al ejercicio democrático que suponen las consultas públicas. Por una parte, las consultas no deberían servir para rescatar a los gobernantes de sus debilitadas capacidades sino para empoderar a la ciudadanía en procesos complejos de toma de decisiones. Las consultas corren un serio peligro cuando no son para los gobernados, cuando se utilizan como un instrumento para ayudar a los gobernantes. La distinción entre los resultados valorados en el corto y en el largo plazo refuerza 
esta idea al mostrarnos como las soluciones a corto pueden ayudar a los gobernantes, pero no tener un impacto satisfactorio sobre el conjunto de la ciudadanía en el largo plazo.

Cuando esto sucede, las consultas se vacían de contenido sustantivo y no interesan a la ciudadanía, se convierten en un juego de artificios tan llamativo como pasajero. En cambio, si las consultas se ponen al servicio de una ciudadanía y si, en realidad, es esta quien las propone y las organiza, entonces sí podríamos encontrarnos ante un cambio real en las relaciones democráticas entre los gobernados y los gobernantes. Tendríamos, en definitiva, que sacar las consultas del control de los gobernantes y, con las regulaciones que se consideren oportunas, colocarlo en manos de los ciudadanos. Sabemos - por ejemplo, a través de estudios sobre la Iniciativa Legislativa Popular (Alarcón et al. 2017) - que situar el impulso y la responsabilidad en la ciudadanía puede producir también distorsiones en la agenda pública, así como favorecer a determinados grupos que pueden estar bien organizados y no necesariamente expresar adecuadamente los intereses colectivos. Será necesario, por lo tanto, discutir y explorar donde está el equilibrio entre la apropiación ciudadana de las consultas y un marco regulador que impida un uso perverso de las mismas.

Por otra parte, también para superar la fugacidad de algunas experiencias consultivas, parece importante tanto que el objeto sea una decisión de política pública que vaya más allá de una dificultad puntual como que los resultados se puedan implementar de manera efectiva. Tener como objeto una política pública nos permite situar la consulta en un contexto más amplio, mientras que asegurar su implementación -usando mecanismos de seguimiento y sanción- vuelve a situar a la ciudadanía en el centro de las consultas. Deberíamos, en otros términos, recuperar unas consultas que en lugar de encontrar sus orígenes en las dificultades decisionales de los gobernantes o en el efecto policy diffusion que generan las moda, exploren su potencial para hacer frente tanto a la creciente capacidad de la ciudadanía como a los problemas de confianza de los gobernantes. Desde esta óptica, las políticas públicas serían el lugar de encuentro y las consultas un instrumento para potenciar su impacto en términos de mejoras para el conjunto de la comunidad.

"De la legitimación institucional al empoderamiento ciudadanos", una idea que recogemos en el título del artículo y que, al mismo tiempo, nos parece la conclusión más sintética del mismo. Una conclusión que nos permite sugerir que, en último término, las consultas deben ser más ciudadanas en el doble sentido de tener a los ciudadanos como protagonistas y a los problemas de estos ciudadanos en el centro de sus objetivos. 


\section{REFERENCIAS}

Alarcón, P., García-Espín, P., Welp,Y. y Font, J. (2018). Influencing politics with signatures? Barcelona: Ajuntament de Barcelona.

Altman, D. (2010). Direct democracy wordwide. Cambridge: Cambridge University Press.

Barber, B. (2004). Democracia Fuerte. Granada: Almuzara.

Blanco,I. y Gomà, R. (2016). El municipalisme del bé comú. Barcelona: Icaria.

Bowler, S. y Donovan, T. (2000). California's experience with direct democracy. Parliamentary Affairs, 53 (4), 644-656.

Brugué, Q. et al. (2011). Democràcia i participació ciutadana. realitat $i$ futur als municipis petits de Catalunya. Barcelona: IGOP-UAB.

Budge, I. (1996). The new challenge of direct democracy. Cambridge: Cambridge University Press.

Canovan, M. (1999). Trust the people! Populism and the two faces of democracy. Political Studies, XLVII, 2-16.

Cooke,B. y Kothari,U. (2001). Participation, the new tyranny. Londres: Zed Books.

Craig, S., Kreppel, A. y Kane, J. (2001). Public opinion and support for direct democracy. Political Science and Politics, 21 (3).

Crerighton,J. L. (2005). The public participation handbook. San Francisco: Jossey-Bass.

Crouch, C. (2004). Posdemocracia. Madrid: Taurus.

Dalton,R. J. (2004). Democratic challenges, democratic choices: the erosion of political support in advanced industrial democracies. Oxford: Oxford University Press.

Delwit, P. (Ed.) (2007). Towards DIY-politics. Participatory and direct democracy at the local level in Europe. Brugge: Vanden Broele. 
Fischer, F. (2003). Reframing public policy. Discursive politics and deliberative practices. Oxford: Oxford University Press.

Font, J. y Gómez, B. (2017) El uso de los referéndums en las democracias europeas. Barcelona: Pensamiento Crítico.

Forester, J. (1999). The Deliberative practitioner. Cambridge: The MIT Press.

Fung, A. (2015). Putting the public back into governance: the challenges of citizen participation and its future. Public Administration Review, 75 (4), 513-522.

Gamper, A. (2015). Forms of democratic participation in multi-level systems. En Fraenkel-Haeberle,S. et al. (Eds.), Citizen participation in multi-level democraces. Leiden: Brill Nijhoff.

Green,J. E. (2010). The eyes of the people. democracy in an age of spectatorship. Oxford: Oxford University Press.

Gutmann, A. y Thompson, D. (2004). Why deliberative democracy? Princeton: Princeton University Press.

Hagen, M. (2002). Direct democracy in practice: The Iniciative as a legislative institution? Congress \& the Presidency, 29 (29), 217-223.

Haskell, J. (2001). Direct democracy or representatives government. Dispelling the populist myth. Oxford: Westview.

Hay, C. (2007). Why we hate politics. Londres: Polity.

Hug, S. (2004). Occurrence and policy consequences of referendums: a theoretical model and emprirical evidence. Journal of Theoretical Politics, 16 (3), 321-356.

Jäske, M. (2017). Soft forms of direct democracy: explining the occurrence of referenum motions and advisory referendums in Finnish local government. Swisss Political Science Review, 23 (1), 50-76.

Kaufman, B., Büchi, R. y Braun, N. (2007). Guía de la democracia directa en Suiza y más allá. Wabern: Initiative \& Referendum Institute Europe.

Leduc, L. (2003). The politics of direct democracy. Referendums in a global 
perspective. Peterborough: Broadview.

Manin,E. (1998). Los principios del gobierno representativo. Madrid: Alianza Editorial.

Mansbridge,J. J. (1983). Beyond adversary democracy. Chicago: The Chicago University Press.

Morel, L. (2001). The Rise of Government-iniciated Referendumns in consolidated democracies. En Mendelsohn, M. y Parkin, A. (Eds.), Referendum democracy. Citizens, elites and deliberation in referendums campaigns. Londres: Palgrave.

Pindado, F. (2015). Recuperar la ciutadania: desenvolupar la democracia directa. En Brugué,Q., Pindado,F. y Rebollo, O. (Eds.), Democràcia local en temps d'incertesa. Barcelona: UAB-ACM.

Reynaert, H. (Ed.) (2005). Revolution or reformation? Reforming local politics in Europe. Brugge: Vanden Broele.

Sánchez-Cuenca,I. (2014). La impotencia democrática. sobre la crisis politica en España. Madrid: Catarata.

Sartori, G. (2007). ¿Qué es la democracia? Barcelona: Taurus.

Schiller, T. (Ed.) (2011). Local direct democracy in Europe. Wiesbaden: VS Verlag.

Schiller,T. y Setälä,M. (Eds.) (2012). Citizens' initiatives in Europe: procedures and consequences of agenda-setting by citizens. Basingstoke: Palgrave Macmillan.

Tilly, C. (2010). Democracia. Madrid: Akal.

Urquizu, I. (2016). La crisis de representación en España. Madrid: Catarata.

Vallespín,F. y Bascuña,M. (2017). Populismos. Madrid: Alianza Editorial.

Verhulst, J. (2006). Direct democracy. Facts and arguments about the introduction of initiative and referendum. Zurich: Democracy International.

Welp,Y. y Ordońez,V. (2017). La democracia directa a debate: procesos y 
BRUgué ET AL.

mecanismos de participación ciudadana. Revista de Pensament i Anàlisi, 21, 9-14.

Zimmerman,J. F. (1999). The New England town meeting. Democracy in action. Westport: Praeger.

Recibido: 05-02-2019

Aceptación de la versión final: 12-06-2019 